\title{
Nigerian Agriculture Promotion Policy 2016 - 2020: Towards a New Paradigm for Domestic Food Security and Foreign Exchange Earnings in Agricultural Production
}

\author{
Dr Heineken Lokpobiri \\ Honourable Minister of State for Agriculture and Rural Development, Abuja, Nigeria
}

\begin{abstract}
Agriculture is key to overall economic growth and development of African countries like Nigeria. A suitable policy that charts a clear roadmap to large scale and commercial agricultural production is necessary to achieving food sufficiency and exports. This paper reviews the Nigerian Agriculture Promotion Policy 2016 2020 (APP) in order to determine how it addresses the challenges that have stifled the growth of agriculture in Nigeria, and the attendant negative impacts on the socio-economic development of the country. The adopted methodology is a desk review and content analysis of the Policy Document, together with other literature on Nigeria's experience in agriculture policy administration. This paper finds that the APP clearly provides a new paradigm in approach and processes towards attaining food security and foreign exchange earnings in Nigeria's agricultural production in the short, medium and long terms. This paper however recommends that in order for the APP to endure for stable and consistent implementation of its long term solutions to Nigeria's agricultural challenges, it should be presented to the National Assembly for enactment as a piece of legislation. This is necessary to sustain the current successes and realize the future potentials of Nigeria's agricultural production as suitably laid out in the APP.
\end{abstract}

Keywords: Agriculture policy, agricultural production, economic development, food security, foreign exchange earnings

DOI: $10.7176 / \mathrm{PPAR} / 9-3-07$

Publication date:March $31^{\text {st }} 2019$

\section{Introduction}

In developing African countries millions of people are engaged in agriculture. But for many decades this has been largely on a small scale or subsistence level, and mostly as a source of livelihood for rural dwellers. In Nigeria the limitation of small scale farming or subsistence agriculture is that it leads to rural-urban migration of young people who leave behind an ageing farming population that cannot sustain agricultural production sufficient enough to cater for the food needs of the country. In addition to food insecurity which it engenders, rural-urban migration of young people contributes to rate of unemployment in urban areas, and lack of productivity of the young population increases the level of poverty in the country. Thus, Nigerian agriculture policies since the last two decades of the 20th century have included efforts to foster the development of medium and large scale commercial agricultural production systems that involve the active participation of the youth population (FMAWRD, 1996).

Agriculture policies to facilitate commercial farming systems are necessary to achieving the immense benefits which modern agriculture offers in terms of increased national productivity, and economic growth and development. For examples, a large scale farming system offers the opportunity for land consolidation and a wide scope for increased productivity through the application of scientific management techniques, the use of modern inputs and the efficient utilization of productive farm resources due to economies of scale. It ensures relative ease and the low cost of handling and marketing large bulks of agricultural commodities. Also, large scale agriculture with a high participation of the young population constitutes gainful employment thereby improving the socio-economic well-being of the citizenry (Shittu, 2017; Ojong \& Anam, 2018). But most significant in the new Agriculture Promotion Policy 2016 - 2020 of the current President Muhammadu Buhari's administration is a paradigm shift from Nigerian oil-dependent and monoculture economy towards a diversified agro-driven economy.

Crude oil has remained the main-stay of Nigerian economy since the 1970s, and a culture of over-reliance on crude oil through the years has since been identified as the bane of low agricultural development in the country. For instance, with over $80 \%$ of arable land only about $40 \%$ is cultivated while agriculture generally contributes a paltry $25 \%$ to Nigerian Gross Domestic Product (Shittu, 2017). Ironically, at the dawn of independence from Britain in 1960 and before the discovery of crude oil, agriculture was the engine of Nigeria economy as the country was a leading producer and exporter of cash crops such as cocoa, groundnut, palm oil, cotton and rubber which collectively accounted for over $90 \%$ of the country's GDP. Cultivation of cassava, yams, rice, various species of cereals, vegetables and fruits ensured food sufficiency in the country and made Nigeria the food basket of Africa (Ibietan, 2011). But a steady decline in Nigeria's agricultural productivity in the last 
three decades led to massive importation of food such as rice, livestock and fish products, and many other agricultural products to meet the national consumption demand. Low agricultural productivity has reflected negatively in the socio-economic development of Nigeria with a relatively high poverty and unemployment rates, including the underdevelopment of rural areas and infrastructure (Oulwaseyi, 2017).

Policies to stem the decline and revamp the agriculture sector in Nigeria have been churned out particularly since the restoration of democratic rule in 1999 (Iwuchukwu \& Igbokwe, 2012). What is now evident is that in spite of crude oil, agriculture remains the base of the Nigerian economy, and it continues to provide the main source of livelihood for most Nigerians. The various policies that have been formulated under different Nigerian governments show that agriculture still remains the largest sector of the Nigerian economy and employs twothirds of the country's entire labour force. However, the sector remains bedevilled with challenges such as outdated land tenure system that constrains access to land with about 1.8 million ha/farming household, a very low level of irrigation development of less than 1 percent of cropped land under irrigation, limited adoption of research findings and technologies, high cost of farm inputs, poor access to credit, inefficient fertilizer procurement and distribution process, inadequate storage facilities and poor access to markets have all combined to keep agricultural productivity low at an average of 1.2 metric tons of cereals/ha, with high post-harvest losses and waste (FAO, 2015).

In the last 16 years, value-added per capita in agriculture has risen by less than 1 percent annually and it is estimated that Nigeria has lost about USD 10 billion in annual export opportunity from groundnut, palm oil, cocoa and cotton alone due to continuous decline in the production of these commodities (FMARD, 2016). Food crop production increases have not kept pace with population growth, resulting in rising food imports and declining levels of national food self-sufficiency. Nigeria is Africa's leading consumer of rice and one of the largest rice importers in the world. In cassava production Nigeria has the capacity to emerge as the largest producer of cassava in the world, with about 50 million metric tons annually from a cultivated area of about 3.7 million hectare. Nigeria currently accounts for cassava production of up to 20 per cent of the world, about 34 per cent of Africa's and about 46 per cent of West Africa's. However, the national average yield of cassava is estimated at about 13.63 metric tons per hectare, as against potential yield of up to 40 metric tons per ha (FMARD. 2016). The Agriculture Transformation Agenda policy of the past Government of Nigeria (2011 2015) expressed determination to end the era of food imports, particularly rice, and develop cassava and rice value chains to produce and add value to these selected products, and create domestic and export markets for farmers. Like in other areas of agricultural production, past agricultural policies in Nigeria have not been as successful as envisaged. The rate of food imports is still very high while exports for foreign exchange earnings are at their lowest ebb.

The thrust of this paper is to closely examine the Nigerian new Agriculture Promotion Policy $2016-2020$ in order to determine what it offers and how it addresses the challenges that have stifled the growth of agriculture in Nigeria, and the attendant negative impacts on the socio-economic development of the country. The adopted methodology is a desk review and content analysis of the Policy Document to show the strengths and weaknesses of the Policy, and the core strategies towards achieving its declared objectives. In order to fully understand the context in which the Policy can be distinguished from previous agriculture policies in Nigeria, the paper highlights the milestones in the history of agriculture polices in the country. This approach is important because the Agriculture Promotion Policy 2016 - 2020 needs to be appreciated from the perspective of how it presents a new paradigm to ensure domestic food security and foreign exchange earnings in agricultural production in Nigeria.

\section{Background: A Highlight of Previous Nigerian Agriculture Policies}

Today, countries across the world are crafting suitable agriculture policies towards achieving the benefits of a vibrant and thriving agricultural sector; provision of food, raw materials for industries, employment generation, and socio-economic, rural and infrastructural developments. In pre-1960 Nigeria, these benefits of agriculture were clearly identified under colonial agriculture policies that ensured adequate production of food and export crops. Nigerian agriculture grew at a rate that provided sufficient food for an increasing population, raw materials for a budding industrial sector, increase in public revenue and foreign exchange for government, and employment opportunities for an expanding labour force. Since there was self-sufficiency in food production the colonial agricultural policies were mainly focused on the production of export crops like cocoa, groundnut, palm produce, rubber and cotton (Olorunfemi \& Adesina, 1998; Ibietan, 2011;).

In the first decade between 1960, when Nigeria became an independent nation, and 1970, after a bloody civil war, Nigerian agriculture policy was not radically different from that of the colonial period (Usoro, 1997). However, indications of problems in agriculture started to emerge as from the early 1970s as evident from increasing food supply short-falls, rising food prices and declining foreign exchange earnings from agricultural exports (Ibietan, 2011). Undoubtedly, the effect of the three-year civil war played a part in the decline of agriculture during this period and it was compounded by the discovery of crude oil in commercial quantities. 
Thus, the period between 1970 and 1980, the second decade after Nigeria's independence, witnessed a rapid deterioration in the country's agriculture sector. Not only were there widening food supply-demand gaps and rising food import bills, there were also rapid declines in government revenue from agriculture, in foreign exchange earnings from agricultural exports and in the labour force required in agriculture. The "oil boom" created serious distortions in the Nigerian economy and accelerated the rate of migration of labour from the agricultural sector (FMAWRD, 1996).

As a way to tackle these challenges a number of agricultural policies were initiated within the framework of three successive rational development plans from 1970 to 1974 , from 1975 to 1980 and from 1981 to 1985 (Iwuchukwu \& Igbokwe, 2012). Between 1970 and 1980, a major agricultural policy promulgated by the then military regime was the National Accelerated Food Production Programme (NAFPP) in 1972. The objective of this policy was to establish national farms with irrigation schemes for large scale grain production throughout the year. The policy also sought to encourage large commercial farms in order to boost the production of food crops for local consumption and export crops to increase the country's GDP. Large national and commercial farms to be situated in rural areas were expected to trigger integrated rural and infrastructural development projects. The NAFPP was designed to be driven by farmers' cooperative societies who would receive disbursements of credits and farm inputs from the government. But this operational arrangement of the programme was also its undoing as the farmers could not form viable cooperatives leading to eventual withdrawal of funding by the government (Adeyeri \& Adejuwon, 2012).

By 1974, another major agricultural policy led to the establishment of Agricultural Development Projects (ADPs) across the country. The ADPs relied on small scale farmers to bring about increase in food production through the application of improved farm inputs like improved seedlings and agro-chemicals provided by government at subsidized rates. The farmers were expected to give feedback information on their field experiences with the new inputs and applications which would serve as data for further improvements. The main objective of the ADPs was to boost food sufficiency and marketability by ensuring increase in farm yields and agricultural productivity at families and households levels of agricultural production. But as a result of the modern inputs provided by government, the ADPs required sole cropping as against mixed or relay cropping usually practiced by rural farmers, and this discouraged farmers' active participation. Also, there was the problem of farmers not getting inputs at the right period. But a common challenge which both the NAFPP and the ADPs could not survive was the high frequency of labour mobility away from agriculture, and government lackadaisical disposition to agriculture (Michael \& Ibrahim, 2003; Iwuchukwu, J.C. \& Igbokwe, 2012; Maku \& Kigbu, 2016 Ojong \& Anam, 2018).

Apathy towards agriculture in the late 1970s was pervasive across the country as petro-dollars from the oil boom discouraged small scale farming while government faltered on implementation of its agricultural policies. Imported food became the trend and salary increases for government workers made the average Nigerian to shun agriculture. The result was the shortage of food and poor nutrition, and the birth of a foreign feeding culture of imported canned food, frozen vegetables, fruits, meats and fish which has endured till this day. Effort towards achieving domestic food sufficiency led to the agricultural policy of Operation Feed the Nation in 1976. The policy was intended to bring about increased food production in the entire nation through the active involvement and participation of everybody in every discipline thereby making every person to be capable of partly or wholly feeding him or herself. Every available piece of land in urban, sub-urban and rural areas was meant to be cultivated while government provided inputs like seedlings, young chicks and livestock, agrochemicals, including farms implements like cutlasses, hoes, spades, and sickles, amongst others at subsidized rates. But this policy could not restore agricultural production to the level of national food sufficiency because farming was essentially done on a past time basis and on fragmented pieces of land, while supply of farm inputs was diverted from actual farmers to people connected to the government establishments (Famoriyo \& Raza, 1981; Muhammad-Lawal \& Atte, 2006;).

Subsequent agriculture policy to boost food production was the Green Revolution of 1980. In fundamental respect this policy was not different form the erstwhile policy of Operation Feed the Nation because it was also aimed at increasing production of food and livestock, including poultry and fishery, through government's provision of improved seedlings, agrochemicals, day old chicks and fingerlings, including credit facilities. But this policy also failed to achieve its objective for reason that had to do with lack of commitment and consistency in implementation of policy strategies by government and relevant stakeholders. For example, credit facilities to farmers at concessionary rate under different agricultural credit guarantee schemes that formed part of the various agricultural policies were either selectively executed in favour of few connected urban farmers, or not implemented at all. There were no government monitoring and evaluation mechanisms to identify operational challenges of the policy in order to ensure effective resolution of the challenges. Also, lack of active participation of key institutional players or shoddy implementation process by corrupt officials was not appropriately sanctioned by government (Iwuchukwu \& Igbokwe, 2012 Fatokun, 2015).

The reasons for the failure of the Green Revolution policy are more or less the same reasons why preceding 
and successive agricultural policies have not achieved the desired objectives of increase in national productivity, self-sufficiency in food production, sustained growth in the agricultural sector, and overall economic development of Nigeria. Through the years and up till 2015 there were various agricultural policies that anchored different agricultural schemes, programmes and intervention funds for the development of agriculture in the country. Most common among them were interventions funds and schemes that specifically focused on micro, small and medium enterprises operating in the agricultural sector, as part of efforts to diversify the economy away from crude oil dependence. These include the N50 billion Agricultural Credit Support Scheme (ACSS) in 2006; the N200 billion Commercial Agricultural Credit Scheme Fund (CACS) in 2009; the N75 billion Nigerian Incentive-Based Risk Sharing System for Agricultural Lending (NIRSAL) in 2011; and the US\$100 million Fund for Agricultural Finance in Nigeria (FAFIN) in 2014. These various funds have not grown the agricultural sector as expected due to the same reasons that are similar to all the failed past agricultural policies in Nigeria.

\subsection{The Policy of Agriculture Transformation Agenda}

It is noteworthy that in the decades before 2015 agriculture policies in Nigeria were no longer purposefully formulated like in the 1970s and early 1980s but as components of broader socio-economic development programmes such as the Directorate of Food, Roads and Rural Infrastructure (1986), the National Agricultural Land Development Authority (1992), the Family Economic Advancement Programme (1996), and the National Economic Empowerment and Development Strategy (1999). There were various other intervention funds and schemes as identified above to promote agriculture with a view to diversifying the oil-based Nigerian economy. But these efforts were not comprehensive enough to contain clear objectives and strategies of a deliberate agricultural policy framework. In 2011, however, the administration of Goodluck Jonathan launched the Agricultural Transformation Agenda (ATA), a policy framework to reform the agriculture sector. The policy was built on the principle that agriculture is a business and therefore strategies should be about realizing the objectives of commercial food production, employment generation and wealth creation. The policy therefore sought to reintroduce the Nigerian economy to sustainable agriculture as business venture driven by the private sector (FMARD, 2016).

The ATA policy provided a platform to re-engage key stakeholders in Nigerian agriculture and shifted focus towards how a self-sustaining agribusiness economy could be built. It focused on how to make Nigeria's agriculture more productive, efficient and effective by setting a target of creating 3.5 million jobs by 2015 , generating foreign exchange, and reducing spending on food imports. Among its key achievements was a restructuring of the fertilizer procurement system through the Growth Enhancement Scheme which registered small holder farmers and provided targeted input subsidies to about 12.5 million farmers between 2011 and 2014 . In addition to granting farmers access to fertilizer and seedlings, commercial banks were engaged to finance the Scheme and boost lending to agriculture from $1 \%$ to $6 \%$ of all formal credit by 2015 . The ATA policy created special funds to support farmers, revived the Bank of Agriculture, and established the Nigerian Incentive-Based Risk Sharing System for Agricultural Lending (NIRSAL) and the Fund for Agricultural Finance in Nigeria (FAFIN). Staple crop processing zones for cassava and rice paddy were designated across the country, and there were concessions of moribund government warehouses and storage assets. New higher yielding crop varieties of Cocoa and rice were introduced, leading to increase in domestic food production by an incremental 20.1 million tons 2014 (FMARD, 2016).

However, like previous agricultural policies, the potential success of the ATA was severely curtailed by myriad of challenges such that it could not deliver on its major objectives. For example, Nigeria still imports about $\$ 3$ to $\$ 5$ billion worth of food annually, especially wheat, rice, fish and sundry items, including fresh fruits. Credit access particularly for small holders remains low and a backlog of unpaid loans due to production losses has discouraged bank lending. Also, there was no synergy or adequate coordination between the Federal and State governments as some of the States undertook actions such as direct procurement of fertilizer contrary to the ATA policy objective under the Growth Enhancement Scheme. Wastage levels remain high in production areas, reducing supply of feedstock to processing factories, and requiring continuous import of supplies. The net effect is limited job growth across the agriculture value chain from input production to market systems, and continued use of limited foreign currency earnings to import vast quantities of food. Thus, the summary of the ATA policy failure is that food crop production increases have not kept pace with population growth, resulting in rising food imports and declining levels of national food self-sufficiency (FMARD, 2016). The table below shows the gaps in Nigeria demand and supply across staple food items as at 2016. 
Table 1: Gaps in Nigeria Demand and Supply of Staple Food Items

\begin{tabular}{|c|c|c|c|}
\hline Crop & $\begin{array}{l}\text { Demand } \\
\text { (tons) }\end{array}$ & $\begin{array}{l}\text { Supply } \\
\text { (tons) }\end{array}$ & Observations \\
\hline Rice & 6.3 million & 2.3 million & Insufficient supply chain integration remains issue \\
\hline Wheat & 4.7 million & 0.06 million & $\begin{array}{l}\text { Driven by demand for various types of wheat (white, hard, durum), } \\
\text { etc. for bread, biscuits and semovita }\end{array}$ \\
\hline Maize/Corn & 7.5 million & 7.0 million & Limited imports required but can shift due to feed demand \\
\hline Soya Beans & $\begin{array}{l}0.75 \\
\text { million }\end{array}$ & 0.6 million & Animal feed and protein cost alt. driving demand \\
\hline Chickens & $\begin{array}{l}200 \text { million } \\
\text { birds }\end{array}$ & $\begin{array}{l}140 \text { million } \\
\text { birds }\end{array}$ & $\begin{array}{l}\text { Gap filled by illegal imports that enter market at lower price point } \\
\text { than domestic producers; gap also a moving target based on fast } \\
\text { food/QSR demand }\end{array}$ \\
\hline Fish & 2.7 million & 0.8 million & $\begin{array}{l}\text { Fall off in ocean catch and weakness in aquaculture yields due to } \\
\text { cost of fish feed a constraint on growth }\end{array}$ \\
\hline Milk/Dairy & 2.0 million & 0.6 million & $\begin{array}{l}\text { Driven by insufficient milking cows and low yields }(15-25 \\
\text { liters/day versus norm of } 35-40 \text { liters NZ/US) }\end{array}$ \\
\hline Tomatoes & 2.2 million & 0.8 million & $\begin{array}{l}\text { Actual production is } 1.5 \text { million tons but } 0.7 \text { million ton is lost } \\
\text { post-harvest }\end{array}$ \\
\hline Yams & 39 million & 37 million & Limited gap today but volumes expected to rise in planning period \\
\hline Oil Palm & 8.0 million & 4.5 million & $\begin{array}{l}\text { Refers to fresh fruit bunch (FFB) from which oil is extracted at a } \\
10 \%-15 \% \text { efficiency rate }\end{array}$ \\
\hline Cocoa & 3.6 million & 0.25 million & Demand is global demand which will rise to 4.5 million by 2020 \\
\hline Cotton & 0.7 million & 0.2 million & $\begin{array}{l}\text { Demand is for seed cotton and could rise to } 1.0-1.5 \text { million tons } \\
\text { subject to textile sector revival }\end{array}$ \\
\hline Sorghum & 7.0 million & 6.2 million & $\begin{array}{l}\text { Demand will rise further as use in feed grows in } 2016-2020 \text {. } \\
\text { Import of malt extracts and glucose syrup is currently used to } \\
\text { manage gap, hence a commercial threat for Nigerian farmers }\end{array}$ \\
\hline
\end{tabular}

Source: Federal Ministry of Agriculture and Rural Development 2016

\section{The Agriculture Promotion Policy 2016 - 2020}

The ATA policy refocused national attention on the agricultural sector after years of benign neglect, and laid the foundations for rebuilding the sector. But in spite of the efforts made under the policy, the state of agricultural development in Nigeria demands that much work needs to be done. For example, the significant short-fall in the supply of food necessitates high food imports and this means capital flight instead of foreign exchange earnings from agriculture (FMARD, 2016). The experience from all the previous and failed agricultural policies means that there is no alternative to a well-designed and implementable agricultural policy framework that can set a steady trajectory towards agricultural growth and development in Nigeria. It is in this light that the current Buhari's administration has painstakingly formulated a comprehensive package of policy instruments - the Agriculture Promotion Policy 2016-2020 (APP) - to establish Nigeria's agricultural sector on the path of sustained growth and development.

The APP recognizes two problems in the development of agriculture in Nigeria: an inability to meet domestic food requirements, and an inability to export at quality levels required for market success and foreign exchange earnings. The first problem is a productivity challenge driven by an input system and farming model that is largely inefficient due to an aging population of farmers who lack access to improved and adequate seedlings, fertilizers, irrigation, crop protection and related support that ensure a successful agricultural production. The second problem is driven by an equally inefficient system for setting and enforcing food quality standards. For example, insufficient food testing facilities, a weak inspectorate system and poor coordination by relevant government agencies compound early stage problems such as lack of knowledge of permissible contaminant levels. Setting Nigeria's agriculture sector on the path of sustained growth and development therefore requires actions to solve the two problems by producing enough fresh, high quality foods for the Nigerian market, and serving the export market successfully to earn foreign exchange.

Thus, the APP is a new policy strategy that aims at solving the core issues at the heart of limited food production and delivery of quality standards for international markets. As agricultural productivity improves domestically and standards are raised for Nigerian food production, export markets will also benefit thereby impacting positively on Nigeria's balance of payments. The Nigerian Federal Ministry of Agriculture and Rural Development (FMARD), in consultation with all relevant stakeholders, has therefore presented the APP as a roadmap to agricultural development in the country. Essentially, the APP gives priority to improving productivity in a number of domestically focused food crops such as rice, wheat, maize, fish, dairy milk, soya 
beans, poultry, horticulture (fruits and vegetables), and sugar. The policy envisages that the problem of domestic food security can be addressed by partnering closely with private investors, farmers' groups and companies to develop end to end value chain solutions. Agricultural producers will receive government's support as they make deep commitments to engaging a new generation of farmers, improving supply of specialized fertilizers and agrochemicals, as well as wider scale use of high yielding seeds. The Nigerian government is expected to work with private investors to effectively improve the distribution system for fresh foods so as to reduce time to table, reduce post-harvest losses, and improve nutritional outcomes e.g. lowering of diabetic risk, stunting risk, amongst others.

The APP also prioritizes food production for export markets and places emphasis on crops such as cowpeas, cocoa, cashew, cassava, ginger, sesame, oil palm, yams, fruits and vegetables, beef and cotton. It proposes that government must work with a network of investors, farmers, processors and other stakeholders to deepen the supporting infrastructure in order to ensure that quality standards are defined and maintained across the value chain. This will involve adding more testing laboratories, improving traceability of crops, disseminating intelligence on export markets and consumer preferences, amongst others. The goal is to build a high quality brand for Nigerian foods based on rigorous data and processes that protect food safety for both domestic and export market consumers. In the implementation of these strategies the APP expects the Federal government to work closely with the State and Local governments while the FMARD will evolve to become a more focused policy maker and regulator towards ensuring results and accountability.

With the FMARD providing intense oversight, the APP lays out specific strategies to facilitate investments in rural roads, reduce farm transportation time, improved security in farming communities, reduce incidence of criminality, and lower intra-State taxes and levies. The oversight will ensure that farmers and investors are working in a market that is safe, competitive, and capable of enabling wealth creation in the coming years. There is plan under the APP to ensure periodic publication of metrics to track performance against the strategy, e.g. tonnage of rice paddy produced, or milking yields of cow. The systems to repeatedly collect accurate data and integrate these into policy making, as well as investor planning are expected to be refined by 2020 . The APP anticipates that key gaps in the Nigerian sector such as continued imports of rice and fresh vegetable will disappear, while Nigerian food products will once again become a quality benchmark across the globe. Reaching that point will require significant investments in people, processes and systems which the APP has clearly identified as current challenges in the Nigeria's agricultural sector.

\subsection{Nigeria's Agricultural Challenges under the APP}

As a policy framework that aims to put Nigeria on a steady path to food security, food export, job creation and economic diversification, the APP clearly identifies the underlying challenges that have bedevilled the agricultural sector for decades. Achieving these aims and unlocking Nigeria's full agricultural potential therefore requires that the following underlying challenges are effectively addressed.

1. Policy Framework: From the highlight of Nigeria's history of agricultural policies since attaining independence in 1960, it is evident that the country suffers from policy instability due to the high rate of turnover of agricultural policies. This has made consistent and successful implementation of such policies impossible, with the result of a problematic development pathway for agriculture; lack of policy accountability, transparency and due process of law, relating to wilful violation of the constitution and subsidiary legislations governing the agriculture sector. This has also made the business environment unpredictable and discourages agricultural investors. The APP recognizes that in order to address this challenge Nigeria needs a suitable and enduring policy framework for agricultural rejuvenation in the country.

2. Political Commitment: This relates to the non-implementation of international protocols or conventions on agricultural development agreed to with other members of the comity of nations. For example, Nigeria has failed to achieve the targets in the Maputo Declaration that prescribes a minimum of $10 \%$ budgetary allocation to the agricultural sector. This political commitment is also lacking at the State governments level where agricultural policy and reforms are not fully adopted and implemented.

3. Agricultural Research and Technology: The APP identifies persistent shortcomings of the National Agricultural Research System (NARS) to generate and commercialize new agricultural technologies that meet local market needs. NARS's shortcomings have been relatively severe particularly around improved varieties of seedlings, breeds of livestock and aquatic species. The failure to deliver already proven technologies available on the shelf to farmers' fields where they are needed is also a challenge. Addressing these will require better coordination among extension delivery system, the national agricultural research system, as well as public and private sector suppliers of agricultural inputs.

4 Infrastructure Deficit: Nigeria's agricultural sector suffers from an infrastructure challenge. Infrastructure such as good motor roads, rail lines and irrigation dams are either insufficient, or when available, not cost competitive. They are thus unable to operate to support large scale agriculture. The consequence is post-harvest waste and an added cost of about $50 \%-100 \%$ on the delivered price of agricultural produce in Nigeria, which makes it 
uncompetitive in comparative terms with other countries. In order to boost farm productivity, raise the level of marketable surplus and expand value chain participants' access to low cost and quality infrastructure, Nigeria will need to rethink the business and operating models for agricultural infrastructure in the country.

5. Finance and Risk Management: The APP notes that Nigeria's agriculture sector continues to have poor access to financial services that enable farmers and other agricultural producers to adopt new technologies, improve market linkages, and increase their resilience to economic shocks. Poor access to financial services that enable input suppliers, processors, traders and others in agribusiness to address liquidity and encourage targeted private sector engagement in agriculture remains a challenge. Lending rates still routinely range from $10 \%$ to $30 \%$ subject to whether the borrower is considered prime, has access to low cost, or government-provided financing and credit guarantee. In order to improve financing options and de-risk agricultural value chains Nigeria will need to intensify innovation in financing the agricultural sector.

6. Institutional Reform and Realignment: In Nigeria today, it is observed that many Federal and State agricultural institutions are absolutely idling away. Such institutions do not even contribute any benefit to their resident local government areas which is where a majority of agricultural activities such as farming and fishing take place. The APP notes that there is a need to streamline, clarify mandates and ensure continued accountability for institutional results; boost capacity of agricultural institutions to deliver on their public mandates; add more resources such as about 15,000 extension workers; and set up more operational coordination mechanisms between the Federal and State governments, amongst others.

\subsection{Essential Principles for Agricultural Development under the APP}

The APP is anchored on three main pillars: promotion of agricultural investment, financing agricultural development programmes, and research for agricultural innovation and productivity. In building these pillars to support its agricultural development projections, the APP is driven by some essential principles such as a recognition that agriculture is a business. This means focusing policy instruments on a government-enabled but private sector-led engagement to drive the development of the agricultural sector. The APP recognizes agriculture as key to long-term economic growth and security through directing policy instruments to ensure that the commercialization of agriculture includes technologies, financial services, inputs supply chains, and market linkages. These are important in effectively engaging rural poor farmers as rural agricultural growth will play a key role in the country's successful march towards economic diversification and sustainable development.

The APP also recognizes the principle of food as a human right and thus focuses policy instruments for agricultural development on the social responsibility of government with respect to food security, social security and equity in the Nigerian society; and compelling the government to recognize, protect and fulfil the irreducible minimum degree of freedom of the people from hunger and malnutrition. Through the principle of value chain approach the APP is focusing policy instruments on enterprise development across successive stages of the commodity value chain for the development of crop, livestock and fisheries sub-sectors. This also includes input supply, production, storage, processing, marketing and consumption. Building complex linkages between value chain stages will be an important part of the ecosystem that will drive sustained agricultural growth and economic prosperity for all Nigerians. The APP notes that achieving improved domestic food security and boosting export earnings requires a measure of crop prioritization. Therefore, the production of domestic crops such as rice, wheat, maize, soya beans and tomatoes will be expanded. For export crops, the focus will be on cocoa, cassava, oil palm, sesame, cashew nuts and gum Arabic. Investments in closing infrastructure gaps to accelerate productivity and investment in these crops is another essential principle driving the APP.

The APP identifies the principle of market orientation through focusing policy instruments on stimulating agricultural production on a sustainable basis. This involves stimulating supply and demand for agricultural produce by facilitating linkages between producers and consumers, while stabilizing prices or reducing price volatility for agricultural produce through market-led price stabilization mechanisms such as commodity exchanges, agricultural insurance, amongst others. Under the APP the principle of factoring climate change and environmental sustainability focuses policy instruments on the sustainable use of natural resources like land, soil, water and the ecosystems with the future generation in mind while increasing production, marketing and other allied activities in the agricultural sector. The principle of participation and inclusiveness means that policy instruments contain measures to maximize the full participation of all stakeholders like farmer's associations, cooperatives, development partners and the private sector. This principle places a premium on the role of these groups as agents of agricultural rejuvenation thereby drawing benefits from their policy advocacy roles as sectoral partners and watchdogs.

The APP recognizes the principle of policy integrity as it places emphasis on measures to sanitize the business environment for agriculture. This is in terms of accountability, transparency and due process of law, ensuring efficient allocation and use of public funding, and fighting corruption on all programmes involving public resources. This also applies to compliance with international commitments, protocols and conventions on agricultural development to which Nigeria is a signatory. The APP also recognizes the principle of nutrition- 
sensitive agricultural practices whereby policy instruments pays attention to addressing the issues of stunting, wasting, underweight and other manifestations of hunger and malnutrition with particular reference to the vulnerable groups such as children under the age of five, nursing mothers and persons with chronic illness or disabilities. Agricultural Linkages with other sectors of the economy is also an essential principle recognized under the APP as it focuses policy instruments on the connected relationship between agriculture and other sectors like industries, environment, power, works and water at Federal, State and Local government levels. Within this overall set of policy principles, the APP tasks the Nigerian government to concentrate on providing a conducive legislative environment and agricultural knowledge framework for promoting agricultural development in the country.

\section{A New Paradigm for Agricultural Growth and Development in Nigeria}

In its laudable objective to unlock Nigeria's full potentials in agricultural production and ensure domestic food security and foreign exchange earnings, the APP identifies core challenges and sets out a roadmap towards addressing the challenges. What distinguishes the APP from all other previous and failed agricultural policies in Nigeria is the method of identifying a matrix of challenges in the agricultural value chain from production through domestic consumption to export markets. The APP develops a comprehensive policy choices to act as guidelines for resolving the challenges along three organizing themes; productivity enhancements, crowding in private sector investment, and institutional realignment. Under these three main themes which are only highlighted below, the APP provides a new paradigm in approach and processes towards addressing the endemic challenges in all areas of agricultural development in Nigeria.

\subsection{Productivity Enhancement}

The policy choices under this theme would boost productivity, reduce post-harvest losses, and expand market access related activities. The target outcome is a blend of metrics that includes rises in farm productivity versus base year (\% yield increases), reductions in post-harvest wastes, share of agricultural inputs used in Nigerian by consumer goods companies, and share of Nigerians fresh goods for the export markets. The essential sub-themes adequately addressed in the area of productivity enhancement are; access to land, soil fertility, access to inputs and access to information, production management, storage, processing, marketing and trade. For example, in terms of access to land the APP sets out parameters to facilitate the recognition of land ownership by formal and customary means through land mapping, registration and efficient technological verification of titles to enable land capitalization. There are suitable processes to; incentivize small farmers to pool their fragmented land holdings and raise their productivity; reduce implicit and explicit gender biases in land allocation and titling processes; encourage migration of farmers to places with relative availability of land; facilitate establishment of commercial ranches for cattle thereby reducing incessant confrontations between nomads and farmers; and ensure a balance between economic growth of larger agribusinesses with the economic cost of displacing small farmers as the rural population grows. Land policy under the APP is firmly rooted in spatial predictions of demographic changes in rural areas as rural farmers are indispensable in agricultural production for domestic food security.

In order to ensure soil fertility for maximum production the APP recognizes the need to maintain adequate levels of macro and micro soil nutrients under intensive production systems that remove nutrients from agriculture areas. Accordingly, the APP provides solutions to soil fertility challenges by outlining processes for crop rotation to improve nitrogen fixation; soil fertility reconstruction and fallow periods; use of organic fertilizer and fertilizer quality control; soil and crop specific fertilizer formulation; and improved conservation, reforestation and green belt zones. The problem of poor information exchange and delivery mechanism for farmers, agricultural research institutions and policy formulators is addressed under the APP with strategies to enhance availability of information and knowledge for farmers, agribusiness and policymakers; and promote the emergence of specialized agricultural information and knowledge from targeted research to address farmer priorities.

The APP contains solutions to the problem of access to inputs such as seedlings, fertilizer, livestock and fish feeds which is characterized by late or non-delivery, delivery of sub-standard or counterfeit inputs, and exclusion of rightful beneficiaries. The policy objective is to increase productivity by ensuring access to timely, high quality and price competitive inputs. In the livestock production value chain under the APP, there are processes to enhance availability of improved breeds, production methods, markets and prices, including policy to enhance resistance breeding; promote availably of pest and disease control services, livestock identification and traceability, zoning and compartmentalization of livestock; and modern ranching, abattoir and processing system. There are similar strategies to make fishery/aquaculture inputs available by promoting hatchery development, standardization of hatchery and fish breeding processes.

The APP addresses the challenges of insufficient water and irrigation systems for full year agricultural production through practicable steps to revitalize existing and establish new small (earth) dams and tube wells; 
promote water conservation by harvesting run-off water and reducing desertification by tree planting; and reactivating the River Basin Authorities and transforming their role in water availability and pricing. In the area of boosting mechanized farming, the APP spells out processes to promote private-sector-led mechanization services as well as cooperative solutions for private sector-led tractor hiring system. It also lays out methods to stimulate domestic production of equipment linked with complementary targeted import and standardization of agro-technology. Taking cognizance of the current post-harvest loss rates of up to $60 \%$ for perishable crops, the APP fashions out the right approach to rapidly introduce new storage solutions across Nigerian agricultural production system. Pursuant to the APP approach Nigeria recently invested billions of naira in the establishment of 33 silo complexes, 25 grain aggregation centres, and 9 units of Blumberg warehouses. Strategies for products storage also include the enforcement of minimum moisture content for stored food and promotion of the use of alternative pest control in storage.

In the areas of processing and marketing of agricultural products the APP provides for effective approach towards enforcing quality control and standardization on food crops, livestock and fishery safety in processing zones, particularly in high agricultural produce areas. There is a prescribed system to enhance the capacity and ensure synergy of all relevant government agencies in agricultural commodity trade, and monitor inwards and outwards movements of agricultural produce at the land borders, seaports and airports; and follow developments in the international trade arena for the benefit of market actors in the Nigerian agricultural sector.

\subsection{Crowding in Private Investment}

The APP has designed new models to deepen the private and financial sectors' engagement with the agribusiness value chain. The target outcome is a lower cost of financing and a greater availability of such financing as measured by cost of capital (\%) paid, number of loans issued versus overall credit provision, levels of private capital formation, and the number of participants in the sector. The APP priorities for which crowding in of private investment is a key goal include access to finance and agribusiness development. Processes through which government will make selective interventions in these areas, and encourage private capital to take the lead in driving projects into these spaces are a key paradigm shift from past agricultural policies. The APP notes that agricultural finance is critical for producers of all sizes - small holder, medium size and larger commercial farms - as well as to properly-functioning input supply markets, processors and traders. Thus, it provides avenues for access to finance for farmers from multiple sources such as public capital markets, private equity and other nonbank channels, other than the conventional banking system as had been the practice. These will address insufficient access to credit, inadequate sources for agricultural financing, and prohibitive interest rates for agricultural lending. There are measures to address non-recognition of cooperative and other farming-based organizations by financial institutions, and a pathway for achieving $10 \%$ of all formal credit to go to the agricultural sector, including public sector funding to the minimum of $10 \%$ of the national budget. The APP also maps out strategies required for the development of effective institutional frameworks to facilitate and coordinate the delivery of agribusiness and investment services; revitalization of agribusiness incubation centres and agro-industrial parks.

\subsection{Institutional realignment}

In order to achieve the target outcome of a more engaged agribusiness market space as measured by ease of doing business in the sector, the APP proffers strategies to deepen the capacity of the Federal Ministry of Agriculture and Rural Development and its key agencies to regulate the sector, engage previously excluded stakeholders, lead policy dialogue and broker the necessary agreements to improve the ease of doing business in Nigeria's agriculture space. It identifies ways to boost cooperation and accountability at the State level to ensure that it reforms are consistently implemented, including creating strong partnership with Local governments on farming operations and investment opportunities. The APP proposes entrepreneurship platforms that create a pathway for youth and women to enter the agribusiness economy, including intervention funds targeted at women and youth, capacity building and technical training for women and youth agro-entrepreneurship. Clear parameters are established to address the high rate of rural-urban migration through aggressive rural infrastructure development to attract agro-based investments in rural areas where there is relative abundant farm land. The APP recognizes agricultural research as a critical enabler of overall economic development and thus provides processes to engage institutions in the country to conduct research for increased agricultural productivity, and to make research results available to farmers and other actors in the agricultural sector. The APP is forward-looking as it addresses issues around climate smart agriculture by providing an approach to developing the technical, policy and investment conditions to achieve sustainable agricultural development for food security under climate change. This involves approach to sustainably increase agricultural productivity, build resilience to climate change, reduce greenhouse gases emissions, and increase the adoption of global best practices on climate change, including the aspects of adaptation, mitigation and carbon credit. 


\subsection{Complementing Programmes of the APP}

An additional and significant way the APP has introduced a new paradigm to Nigeria's agricultural development are current complementing agricultural programmes. These programmes are in the form of special purpose vehicles to effectively realize the overall objectives of achieving food security and foreign exchange earnings in Nigeria's agricultural production. Pursuant to the policy choices of the APP towards resolving the endemic challenges in the agricultural sector, key programmes such as the Anchor Borrowers' Programme, Presidential Fertilizer Initiative, Youth Farm Lab, Presidential Economic Diversification Initiative, and the National Food Security Council have been successfully instituted. For example, the Anchor Borrowers Programme (ABP) creates a linkage between companies involved in the processing of certain agricultural commodities and small holder farmers with a view to increasing the agricultural output of small farmers and improving capacity utilization of the agro-processors. The ABP provides seedlings to farmers and cash to grow the crops. At harvest, the small holder farmers supply their produce to the agro-processors who pay the cash equivalent to the farmers' account. This programme is helping to boost production of the selected commodities and make sure there is constant supply of the commodities to the agro processors. The target commodities are staple food crops such as cereals (rice, maize, wheat etc.); roots and tubers (cassava, potatoes, yam, Ginger); including livestock (fish and poultry); amongst others. The ABP is increasing banks' financing to the agricultural sector, reducing agricultural commodity importation, creating new generation of farmers, reducing the level of poverty among small holder farmers, and assisting rural small holder farmers to grow from subsistence to commercial production levels. With the Presidential Fertilizer Initiative that has revived Nigeria's capacity to blend NPK multi-nutrient fertiliser which is now readily available to farmers at subsidized prices, it is noted that under the ABP over 250,000 farmers have successfully cultivated almost 300,000 hectares of farmland for the selected food crops; and that two years into the implementation, the ABP has contributed to the creation of an estimated 890,000 direct and 2.6 million indirect jobs in Nigeria (CBN, 2018).

\section{Conclusion and Recommendation}

Policy administration to rejuvenate Nigeria's agricultural production is essential to addressing the country's socio-economic challenges such as pervasive poverty, high rate of unemployment and poor infrastructure. A fully developed agricultural sector would ensure domestic food security and bring foreign exchange earnings for overall economic growth and development of the country. Without a doubt the APP clearly provides a new roadmap for Nigeria's agricultural development both in the short, medium and long terms; and its complementing programmes are already actualizing its policy choices to tackle the country's agricultural development challenges. What is needed and hereby recommended is that the APP should be presented to the National Assembly for enactment as a piece of legislation. This is for the APP to endure for stable and consistent implementation of its long term solutions to Nigeria's agricultural challenges. The only likely way to roll back the current tremendous success and future potentials of Nigeria's agricultural production under the auspices of the APP is to allow it to be easily disrupted, supplanted or jettisoned by subsequent administration after the Presidency of Muhammadu Buhari.

\section{References}

Adeyeri, O. \& Adejuwon K.D. (2012). The implication of British colonial economic policies on Nigeria's development. International Journal of Advanced Research in Management and Social Sciences, 1(2): 2.

Central Bank of Nigeria (2018). New Guidelines for the Anchor Borrower Programme. Available at: https://www.proshareng.com/news/Agriculture/CBN-Publishes-Anchor-Borrowers--ProgrammeGuidelines/33396 (Accessed October 30, 2018)

Famoriyo, S. \& Raza, R.M. (1981). Green Revolution: Past and Present Prospects for Agricultural Development in Nigeria (Seminar delivered at Department of Agricultural Economics and Rural Sociology, IAR-ABU, Zaria on 21-24 September).

Fatokun, A. (2015). The importance of agriculture towards the development of Nigeria economy. Available at: https://www.linkedin.com/pulse/importance-agriculture-towards-development-nigeria-economy-fatokun (Accessed October 27, 2018).

Federal Ministry of Agriculture and Rural Development, (2016). The Agriculture Promotion Policy (2016 2020): Building on the Successes of the ATA, Closing Key Gaps, Policy and Strategy Document. Abuja: Nigeria

Federal Ministry of Agriculture, Water Resources and Rural Development, (1996) Agricultural Policy for Nigeria. Abuja: Nigeria

Ibietan, J. (2011). Public Policy Making Process: Agricultural and Rural Development Policies in Nigeria (1960 to Date). International Association of Studies in the Humanities, 8, 9

Iwuchukwu, J.C. \& Igbokwe, E.M. (2012). Lessons from Agricultural Policies and Programmes in Nigeria. Journal of Law, Policy and Globalization, 5, 11 
Maku, A.A. \& Kigbu, Y.O. (2016). Federal Government New Policy of Agriculture and Integrated Rural Development: An Appraisal. International Journal of Advanced Academic Research, 2, 1

Michael, J. \& Ibrahim, S. E. (2003). Agricultural Production and the Economic Development of Nigeria. Journal of Development and Society, 1.1: 471-81

Muhammad-Lawal, A., \& Atte, O. A. (2006). An analysis of agricultural production in Nigeria. African Journal of General Agriculture, 2

Ojong, F.E \& Anam, B.E. (2018). Agriculture Promotion Policy 2016-2020 and Rural Development in Nigeria: Challenges and Prospects. Journal of Humanities and Social Science, 23: 24-29

Olorunfemi A, \& Adesina O.C. (1998). Politics and Nigerian agriculture in the first decade of the oil boom, 1970-1980: A preliminary assessment. NJEH: 57-69.

Oluwaseyi, A.B. (2017). The Prospects of Agriculture in Nigeria: How Our Fathers Lost Their Way - A Review Asian. Journal of Economics, Business and Accounting, 4(2): 1-30

Shittu, B. (2017). Agricultural policies to ensure food security, improve nutrition in Nigeria. Available at: https://www.today.ng/news/nigeria/24148/agric-policies-ensure-food-security-improve-nutrition-nigeria. (Accessed October 30, 2018)

The Food and Agriculture Organization of the United Nations. (2015). The state of food and agriculture: Innovation in family farming. Available at: http://www.fao.org/3/a-i4040e.pdf

The Food and Agriculture Organization of the United Nations. (2011). Women in agriculture: Closing the gender gap for development. Available at: http://www.fao.org/docrep/013/i2050e/i2050e.pdf (Accessed October 27, 2018)

Usoro EJ. (1997). Colonial economic development planning in Nigeria, 1919-1939: An Appraisal. The Nigerian Journal of Economic and Social Studies. 9(1). 